УДК 615.12:006.85

DOI https://doi.org/10.11603/2312-0967.2019.3.10403

\title{
МЕТОДОЛОГІЯ РОЗРОБКИ КОМПЛЕКСУ СТАНДАРТНИХ ОПЕРАЦІЙНИХ ПРОЦЕДУР В УМОВАХ УПРОВАДЖЕННЯ НАЛЕЖНОЇ АПТЕЧНОЇ ПРАКТИКИ
}

\author{
Л. О. Гала \\ Національний медичний університет імені О. О. Богомольця, Київ \\ hala.liliia@gmail.com
}

ІНФОРМАЦІЯ

Надійшла до редакції / Received: 25.07.2019

Після доопрацювання / Revised: 30.08.2019

Прийнято до друку / Accepted: 05.09.2019

\section{Ключові слова:}

Належна аптечна практика; стандарти;

стандартна операційна процедура.
АНОТАЦІЯ

Мета роботи. Науково-прикладне обґрунтування підходів до розробки переліку типових стандартних операційних процедур (СОП) та визначення змістового наповнення їхніх складових для забезпечення належного виконання вимог стандартів Належної аптечної практики (GPP).

Матеріали і методи. У дослідженні були використані нормативно-правові акти України й інших країн світу, Спільна настанова Міжнародної фрармацевтичної федерації та Всесвітньої організації охорони здоров'я «Належна аптечна практика: Стандарти якості аптечних послуг» (2011), а також системний та структурно-срункціональний аналіз, зокрема моделювання процесів.

Результати й обговорення. На підставі вивчення досвіду використання національних стандартів GPP за основними напрямами фрармацевтичної діяльності аптек у різних країнах світу та відповідних розробок вітчизняних науковців проведено типологію СОП. Запропоновано перелік найбільш розповсюджених типових СОП відповідно до ролей фрармацевтичних працівників аптеки, які вони виконують у повсякденній діяльності. Керівництво аптеки самостійно вирішує питання щодо розширення зазначеного переліку залежно від спектра фрармацевтичних послуг, що надаються.

За результатами проведеного дослідження, в основу якого були покладені системний, процесний та функціонально-рольовий підходи до організації фрармацевтичної діяльності аптек, запропоновано вісім типів СОП: підготовчі, товарознавчі, виробничі, аналітичні, контролюючі, обслуговуючі, освітні й оціночні.

У зв'язку з відсутністю загально прийнятої процедури розробки СОП запропоновано орієнтовну типову структуру СОП для аптек та ії̈ змістове наповнення, враховуючи наступні вимоги GPP: актуальність, ясність, точність, доступність, зручний фрормат. Для забезпечення доступності подання матеріалу СОП не має дублювати основну інформацію стосовно вимог до фрармацевтичної діяльності, що розміщена в стандарті GPP. Для забезпечення належного виконання вимог GPP запропоновано низку методологічних підходів до розробки СОП.

Висновки. Проведено типологію СОП та запропоновано вісім типів СОП: підготовчі, товарознавчі, виробничі, аналітичні, контролюючі, обслуговуючі, освітні та оціночні, а також перелік найбільш розповсюджених типових СОП за фрункціонально-рольовим підходом до розробки національних стандартів GPP та орієнтовну типову структуру СОП для аптек.

ISSN 2312-0967. Фармацевтичний часопис. 2019. № 3 
Вступ. Для нових незалежних держав, включно України, міжнародні стандарти Належної аптечної практики (Good Pharmacy Practice - GPP) мають рекомендаційний характер. Рекомендації передусім стосуються розробки та впровадження національних стандартів GPP. У них зведені професійні завдання, які стоять перед фрармацевтичними асоціаціями та органами влади, що регулюють роботу фрармацевтичного сектора [1].

Головна проблема впровадження GPP зосереджена на мікроекономічному рівні фрармацевтичної галузі, де практика розглядається як фрілософрія і як керівний принцип професійної діяльності. У рекомендаціях 3 GPP зазначено, що ними можуть користуватись як державні, так і незалежні аптеки, що зацікавлені в ефрективному розвитку своєї діяльності, тобто аптеки приватної й колективної форм власності. Новою парадигмою GPP передбачено фрункціонально-рольовий підхід до створення національних стандартів, який на практиці реалізується шляхом розробки документованих робочих процедур. Таким чином створення стандартних операційних процедур - СОП, є одним з найбільш важливих елементів у системі менеджменту якості надання фрармацевтичних послуг за умов впровадження GPP [1-5].

Науково-методичні проблеми розробки та застосування СОП у практичній діяльності аптечних закладів розглядали у своїх наукових працях: Здорик О. А., Немченко А. С., Лебединець В. О., Коваленко С. М., Тахтаулова Н. О. та інші. Авторами було досліджено проблеми розробки стандартів GPP за окремими напрямами фрармацевтичної діяльності, зокрема присвячених виготовленню екстемпоральних лікарських засобів (Л3), а також стандартизації документообігу в аптеках як основного механізму функціонування системи забезпечення якості [3-5]. Однак методологічні засади створення СОП за умов упровадження GPP залишилися поза увагою.

Мета роботи. Науково-прикладне обґрунтування підходів до розробки переліку типових СОП та визначення змістового наповнення їх складових для забезпечення належного виконання вимог стандартів GPP.

Матеріали і методи. У дослідженні використано нормативно-правові акти України та інших країн, Спільну настанову Міжнародної фрармацевтичної фредерації та Всесвітньої організації охорони здоров'я «Належна аптечна практика: Стандарти якості аптечних послуг» (2011), а також системний та структурнофункціональний аналіз, зокрема моделювання процесів.

Результати й обговорення. СОП, інструкції та пам'ятки є письмовими інструкціями, які регламентують певні аспекти діяльності аптечного закладу. Головною ціллю СОП є ефективна організація фрармацевтичної діяльності аптеки відповідно чинному законодавству, правилам та процедурам, яка $є$ ідентичною для одних і тих же процесів, забезпечує пра- вильність і тотожність типових процесів, та об'єктивно відображає результати діяльності. Таким чином, створення СОП є підґрунтям для гарантування якості виробничих процесів, а відповідно, і результатів роботи окремо взятого аптечного закладу.

Наразі рекомендовані переліки СОП, що пропонуються закордонними фрармацевтичними асоціаціями чи владними установами - це типові шаблони, що $є$ основою для розробки власних СОП, оскільки всі аптеки працюють по різному [6-17]. Саме це положення логічно визначає необхідність розробки власного СОП за структурою типового СОП (СОП для СОП). Це потребує обґрунтування типових СОП для розробки власних СОП, а також внутрішніх інструкцій та пам'яток, які виконують фрункції таких стандартів.

Метою розробки типового СОП для власного СОП є регламентація порядку та процедури щодо фрормування, аналізу й перевірки документів до початку їхнього осріційного використання в аптечному закладі, актуалізації та перегляду документів, які вже використовуються в роботі, правила позначення документів та ідентифрікації будь-яких змін у діючих документах.

На підставі вивчення досвіду використання національних стандартів GPP за основними напрямами фармацевтичної діяльності аптек у різних країнах світу та відповідних розробок вітчизняних науковців нами була проведена типологія найбільш розповсюджених СОП. Запропоновано перелік найбільш розповсюджених типових СОП (табл.), розробка яких, на нашу думку, є доцільною, відповідно до ролей фрармацевтичних працівників аптеки, які вони виконують у повсякденній діяльності.

Зазначений перелік не є вичерпним, оскільки керівництво аптеки самостійно вирішує питання щодо його розширення залежно від спектра фармацевтичних послуг, що надаються.

За результатами проведеного нами дослідження, в основу якого були покладені системний, процесний та фрункціонально-рольовий підходи до організації фрармацевтичної діяльності аптек, були запропоновані вісім типів СОП: підготовчі, товарознавчі, виробничі, аналітичні, контролюючі, обслуговуючі, освітні й оціночні.

Ключовими СОП, безумовно, є обслуговуючі стандарти щодо надання фрармацевтичних послуг пацієнтам, до яких належить відпуск ЛЗ за рецептами лікарів та безрецептурних препаратів, а також надання першої медичної допомоги та консультації 3 питань здоров'я.

Обов'язковими СОП практично для усіх країн $€ \mathrm{C} €$ виробничі, це виготовлення стерильних та нестерильних лікарських фрорм та проведення інших виробничих операцій.

До підготовчих СОП слід віднести забезпечення санітарно-гігієнічного режиму в аптеці та дотримання правил особистої гігієни персоналом, а також реєстрація параметрів повітря та температури.

ISSN 2312-0967. Pharmaceutical review. 2019. № 3 
Організація роботи аптечних підприємств

Organization of pharmaceutical structures' work

\section{Таблиця}

Перелік найбільш розповсюджених типових СОП за функціонально-рольовим підходом до розробки національних стандартів GPP

\begin{tabular}{|c|c|}
\hline $\begin{array}{l}\text { Роль фрармацевтичного праців- } \\
\text { ника }\end{array}$ & Приклади типових СОП \\
\hline $\begin{array}{l}\text { Отримання, виготовлення, } \\
\text { зберігання, відпуск і знешко- } \\
\text { дження ЛЗ і медичних виробів }\end{array}$ & $\begin{array}{l}\text { - забезпечення санітарно-гігієнічного режиму в аптеці; } \\
\text { - дотримання правил особистої гігієни персоналом; } \\
\text { - організація отримання ЛЗ та медичних товарів; } \\
\text { - організація зберігання товарів аптечного асортименту; } \\
\text { - реєстрація параметрів повітря та температури; } \\
\text { - проведення вхідного контролю якості ЛЗ; } \\
\text { - контроль термінів придатності Л3; } \\
\text { - виготовлення нестерильних лікарських форм; } \\
\text { - виготовлення стерильних лікарських фрорм; } \\
\text { - відпуск ЛЗ за рецептами лікарів; } \\
\text { - відпуск безрецептурних препаратів населенню; } \\
\text { - організація роботи із призупинення реалізації ЛЗ, що не підлягають подальшо- } \\
\text { му використанню }\end{array}$ \\
\hline $\begin{array}{l}\text { Забезпечення ефрективної } \\
\text { фрармакотерапії у виборі ЛЗ та } \\
\text { в рамках відповідального са- } \\
\text { молікування }\end{array}$ & $\begin{array}{l}\text { - забезпечення фрармаконагляду в аптеці; } \\
\text { - інфрормаційна робота з лікарями; } \\
\text { - процедура направлення пацієнта до лікаря в разі потреби; } \\
\text { - забезпечення можливості для конфіденційної бесіди; } \\
\text { - надання фрармацевтичної опіки відвідувачам аптеки }\end{array}$ \\
\hline $\begin{array}{l}\text { Професійний розвиток фрарма- } \\
\text { цевтичного персоналу для під- } \\
\text { вищення ефективності діяль- } \\
\text { ності }\end{array}$ & $\begin{array}{l}\text { - порядок навчання персоналу аптеки; } \\
\text { - процедура підвищення кваліфрікації співробітників; } \\
\text { - контроль самонавчання та самооцінки }\end{array}$ \\
\hline $\begin{array}{l}\text { Сприяння підвищенню ефек- } \\
\text { тивності системи охорони гро- } \\
\text { мадського здоров'я }\end{array}$ & $\begin{array}{l}\text { - порядок розгляду відгуків пацієнтів; } \\
\text { - надання першої медичної допомоги; } \\
\text { - надання консультації з питань здоров'я; } \\
\text { - скринінг пацієнтів з високим ризиком захворювання }\end{array}$ \\
\hline
\end{tabular}

До товарознавчих - стандарти з організації отримання та зберігання лз та медичних товарів, які повинні враховувати вимоги належної практики зберігання - GSP. Саме стандарти цієї практики розповсюджуються не тільки на сореру реалізації ліків, а й їхнє виробництво та дистрибуцію. До групи товарознавчих належать також стандарти з організації роботи із призупинення реалізації Л3, що не підлягають подальшому використанню, а також виконання процедури щодо їхнього повернення постачальнику або знищення таких ліків.

До групи контролюючих СОП, які є обов'язковими, слід включити, перш за все, проведення вхідного контролю якості ЛЗ та контролю термінів їхньої придатності.

Особливої уваги в системі забезпечення гарантій якості фрармацевтичних послуг мають аналітичні СОП, до них, на нашу думку, доцільно віднести стандарти стосовно забезпечення ефективної фрармакотерапії у виборі ЛЗ та в рамках відповідального самолікування. Це стосується ситуацій, коли фрармацевт повинен здійснити відпуск препаратів, які призначені лікарем за міжнародною непатентованою назвою або здійснити ефективну генеричну заміну. До таких СОП слід віднести стандарти щодо надання фрарма- цевтичної опіки та забезпечення фрармаконагляду в аптеці; інформаційну робота з лікарями; процедуру направлення пацієнта до лікаря в разі потреби; забезпечення можливості для конфіденційної бесіди, скринінг пацієнтів з високим ризиком захворювання, а також порядок розгляду відгуків пацієнтів. Значення аналітичних СОП зростає за умов упровадження медичного страхування, зокрема механізму реімбурсації вартості Л3. Уже сьогодні про це свідчить досвід аптек, які задіяні в Урядовій програмі «Доступні ліки».

У комплексі стандартів GPP важливу роль мають освітні та оціночні СОП з метою постійного професійного розвитку фрармацевтичного персоналу та підвищення ефективності діяльності аптеки. До освітніх стандартів слід віднести загальний порядок навчання персоналу аптеки та процедуру підвищення кваліфрікації співробітників. Освітні стандарти, на наш погляд, повинні включати контроль самонавчання та самооцінки рівня профресійної компетенції фрармацевтичних працівників.

Слід зазначити, що СОП як документ, що допомагає забезпечити якісне виконання вимог GPP чи інших нормативних документів з питань регулювання фармацевтичної діяльності, має бути індивідуальним для кожної аптеки, враховуючи особливості її ро-

ISSN 2312-0967. Фармацевтичний часопис. 2019. № 3 
Організація роботи аптечних підприємств Organization of pharmaceutical structures' work

боти. У системі управління документацією необхідно чітко визначити правила розповсюдження документів й правила вилучення, або ідентифрікації застарілої документації. У СОП обов'язково необхідно відобразити порядок ідентифікації та поводження 3 документами зовнішнього походження, наприклад: нормативними документами, стандартами, договорами 3 замовниками і т. ін.

Загальноприйнятої процедури написання стандартів не існує, тому ми пропонуємо орієнтовну типову структуру СОП для аптек та її змістове наповнення (рис.), враховуючи наступні вимоги GPP: актуальність, ясність, точність, доступність, зручний фрормат.

Також слід брати до уваги, що основна інформація стосовно вимог до фрармацевтичної діяльності розміщена в стандарті GPP, тому СОП не має її дублювати для забезпечення доступності подання матеріалу.

На підставі проведеного дослідження з питань використання СОП для належного виконання вимог GPP, пропонуємо наступні методологічні підходи до розробки СОП:
- інтеграція досвіду європейських країн щодо розробки СОП із фармацевтичної діяльності;

- необхідність розробки складових та змістового наповнення СОП з урахуванням особливостей фрункціонування конкретного аптечного закладу для забезпечення індивідуальності сОП та відповідності робочим процесам;

- дотримання при написанні СОП вимог щодо простоти, стислості, однозначності, логічності для забезпечення належного виконання;

- виключення дублювання інфрормації, представленої у відповідному стандарті GPP, що пов'язаний 3 конкретною СОП;

- забезпечення навчання персоналу в разі потреби;

- обов'язкова документація процесів уведення в дію та ознайомлення працівників зі змістом СОП;

- забезпечення актуальності СОП шляхом періодичного перегляду документів й оновлення в разі потреби (зміни орармацевтичного законодавства, зміни всередині організації тощо).

Конкретний перелік власних СОП та порядок їхньої розробки повинен бути встановлений вже при

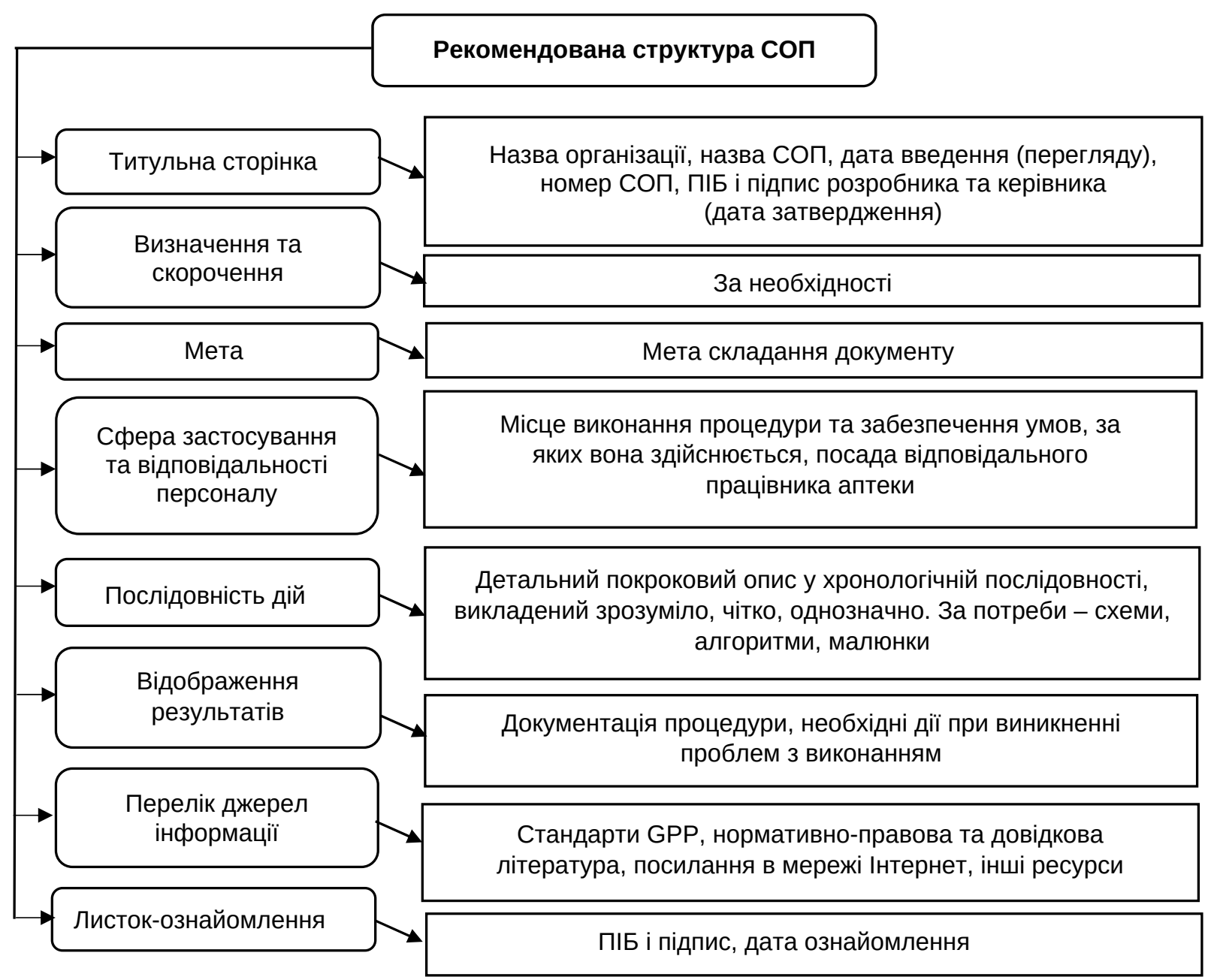

Рис. Рекомендована типова структура та змістове наповнення СОП згідно з вимогами GPP.

ISSN 2312-0967. Pharmaceutical review. 2019. № 3 
Організація роботи аптечних підприємств Organization of pharmaceutical structures' work

попередньому аналізі стану роботи аптеки та виявленні головних і другорядних проблем. Розроблені СОП можуть включати посилання на відповідні інструкції, правила та інші СОП, які мають бути доступні фрармацевтичному персоналу. Усі підготовані СОП мають бути на відповідних робочих місцях. Крім того, доцільно підготувати скорочені пам'ятки щодо послідовності виконання робіт, які повинні бути перевірені і затверджені керівництвом, а також розміщенні на робочих місцях, разом із СОП.

Висновки. 1. На основі аналізу досвіду використання національних стандартів GPP за основними напрямами фрармацевтичної діяльності аптек у різних країнах світу та відповідних розробок вітчизняних науковців проведено типологію найбільш розповсюджених СОП, а також запропоновано вісім типів СОП: підготовчі, товарознавчі, виробничі, аналітичні, контролюючі, обслуговуючі, освітні та оціночні.

2. Запропоновано перелік найбільш розповсюджених типових СОП за фрункціонально-рольовим підходом до розробки національних стандартів GPP, який не $є$ вичерпним, оскільки аптека самостійно вирішує питання щодо його розширення залежно від спектра фрармацевтичних послуг, що надаються.

3. Розроблено орієнтовну типову структуру СОП для аптек та їх змістове наповнення, враховуючи наступні вимоги GPP: актуальність, ясність, точність, доступність, зручний формат.

Конфлікт інтересів: відсутній.

Conflicts of interest: author has no conflict of interest to declare.

\title{
METHODOLOGY OF DEVELOPING A COMPLEX OF STANDARD OPERATING PROCEDURES IN CONDITIONS OF IMPLEMENTATION GOOD PHARMACY PRACTICE
}

\author{
L. O. Hala \\ O. Bohomolets National Medical University, Kyiv \\ hala.liliia@gmail.com
}

The aim of the work. Scientific and applied grounding of approaches to the development of the list of typical standard operating procedures (SOPs) and to determine the semantic content of their components to ensure proper compliance with the requirements of Good Pharmacy Practice (GPP) standards.

Materials and Methods. Laws and regulations of Ukraine and other countries, the Joint International Pharmaceutical Federation and the World Health Organization guidelines "Good Pharmacy Practice: Quality Standards of Pharmacy Services" (2011), and systemic and structural-functional analysis, including process simulation were used.

Results and Discussion. Based on the experience of using national standards of GPP on the main directions of pharmacy activity in different countries and relevant developments of domestic scientists the typology of SOPs was conducted. A list of the most common typical SOPs according to the roles of pharmacists in the pharmacy, which they perform in their daily activities was proposed. Pharmacy management decides itself on the issue of expanding the list, depending on the range of pharmaceutical services provided.

According to the results of the research, which was based on systematic, procedural and functional-role approaches to the organization of pharmaceutical activities of pharmacies, eight types of SOPs were proposed: preparatory, commodity, production, analytical, supervisory, service, educational and evaluation.

In the absence of commonly accepted procedure for the development of the SOPs, the approximate typical SOPs structure for pharmacies and its semantic content was proposed, taking into account the following requirements of GPP: relevance, clarity, accuracy, accessibility, convenient format. To ensure the availability of material, the SOP does not duplicate the basic information on the requirements for pharmaceutical activity that is placed in the standard GPP. A number of methodological approaches to the development of SOPs were proposed to ensure proper implementation of GPP requirements.

Conclusions. Typology of SOPs was conducted. Eight types of SOPs: preparatory, commodity, production, analytical, supervisory, service, educational and evaluation - were proposed, as well as a list of the most common types of SOPs according to a functional-role approach to the development of national standards for GPP and an approximate model of SOP for pharmacies.

Key words: Good Pharmacy Practice; standards; standard operating procedure.

ISSN 2312-0967. Фармацевтичний часопис. 2019. № 3 


\title{
МЕТОДОЛОГИЯ РАЗРАБОТКИ КОМПЛЕКСА СТАНДАРТНЫХ ОПЕРАЦИОННЫХ ПРОЦЕДУР В УСЛОВИЯХ ВНЕДРЕНИЯ НАДЛЕЖАЩЕЙ АПТЕЧНОЙ ПРАКТИКИ
}

\author{
л. А. Гала \\ Национальный медицинский университет имени А. А. Богомольца, Киев \\ hala.liliia@gmail.com
}

Цель работы. Научно-прикладное обоснование подходов к разработке перечня типичных стандартных операционных процедур (СОП) и определение содержательного наполнения их составляющих для обеспечения надлежащего выполнения требований стандартов Надлежащей аптечной практики (GPP).

Материалы и методы. В исследовании были использованы нормативно-правовые акты Украины и других стран мира, Совместное руководство Международной фрармацевтической федерации и Всемирной организации здравоохранения «Надлежащая аптечная практика: Стандарты качества аптечных услуг» (2011), а также системный и структурно-функциональный анализ, в частности моделирование процессов.

Результаты и обсуждение. На основании изучения опыта использования национальных стандартов GPP по основным направлениям фрармацевтической деятельности аптек в разных странах мира и соответствующих разработок отечественных ученых проведено типологию СОП. Предложен перечень наиболее распространенных типичных СОП в соответствии с ролями фармацевтических работников аптеки, которые они выполняют в повседневной деятельности. Руководство аптеки самостоятельно решает вопрос о расширении указанного перечня в зависимости от спектра предоставляемых фармацевтических услуг.

По результатам проведенного исследования, в основу которого были положены системный, процессный и фрункционально-ролевой подходы к организации фрармацевтической деятельности аптек, предложено восемь типов СОП: подготовительные, товароведческие, производственные, аналитические, контролирующие, обслуживающие, образовательные и оценочные.

В связи с отсутствием общепринятой процедуры разработки СОП предложено ориентировочную типовую структуру СОП для аптек и ее содержательное наполнение, учитывая следующие требования GPP: актуальность, ясность, точность, доступность, удобный фрормат. Для обеспечения доступности изложения материала соп не должна дублировать основную информацию относительно требований к фармацевтической деятельности, которая содержится в стандарте GPP. Для обеспечения надлежащего выполнения требований GPP предложен ряд методологических подходов к разработке сОП.

Выводы. Проведена типология СОП и предложено восемь типов СОП: подготовительные, товароведческие, производственные, аналитические, контролирующие, обслуживающие, образовательные и оценочные, а также перечень наиболее распространенных типичных СОП по функционально-ролевому подходу к разработке национальных стандартов GPP и ориентировочная типичная структура СОП для аптек.

Ключевые слова: Надлежащая аптечная практика; стандарты; стандартная операционная процедура.

\section{Список літератури}

1. Належна аптечна практика: Стандарти якості аптечних послуг (Спільна настанова МФФ/ВООЗ з НАП), 2011. URL.: http://zakon4.rada.gov.ua/laws/show/897_009

2. Законодавство України. - URL.: https://zakkon.rada. gov.ua

3. Система качества и надлежащие практики в фрармации : учеб. пособ. / Ю. В. Подпружников, А. С. Немченко, Л. Н. Андрюкова, Н. И. Гуменюк. Киев : ТОВ «СІК ГРУП УКРАЇНА», 2017. - С. 619-651.

4. Zdoryk O. A. Development of standard operating procedures and their introduction in compounding pharmacies. - Вісник фрармації. - 2015. - № 3. - С. 56-59. DOI: 10.24959/nphj.15.2042

5. Лебединець В.О.Регламентація документообігу в системі управління якістю фрармацевтичного підприємства / В. О. Лебединець, С. М. Коваленко, Н. О. Тахтаулова // Управління, економіка та забезпечення якості в фрармації. - 2011. - № 5. - C. 15-20.

6. Leitlinien. - URL.: https://www.abda.de/themen/apotheke/qualitaetssicherungo/leitlinien/
7. Inspektionsprotokoll Drogerien. - URL.: https://www. gef.be.ch/gef/de/index/direktion/organisation/kapa/ formulare.assetref/dam/documents/GEF/KAPA/de/ CL_0510_02_D_V02_Inspro_Dro_\%20Mai2017.pdf

8. Standard Operating Procedures (- SOPS), 2016. - URL.: https://www.thepsi.ie/gns/inspection-enforcement/inspections/InspectorsAdvice/SOPs.aspx

9. Community Pharmacy Benchmarking Guideline. Pharmaceutical Services Division, 2016. - URL.: https://www. pharmacy.gov.my/v2/sites/default/files/document-upload/ community-pharmacy-benchmarking-guideline.pdf

10. Setiawan D. Analisa Standar Operasional Prosedur CV. Apotek Lawang Gali / D. Setiawan // AGORA. - 2018. Vol. 6, № 1. - P. 1-7.

11. Bhattacharya J. Guidance for Preparing Standard Operating Procedures (Sops) / J. Bhattacharya // IOSR Journal of Pharmacy. - 2015. - Vol. 5, № 1. - P. 29-36.

12. Порядок разработки рабочих инструкций и стандартных операционных процедур для аптечных организаций Республики Беларусь, 2007.

ISSN 2312-0967. Pharmaceutical review. 2019. № 3 
Організація роботи аптечних підприємств

Organization of pharmaceutical structures' work

- URL.: http://rceth.by/Documents/3mz6in2007091 8N050-0807.pdf

13. Об утверждении Надлежащей аптечной практики : Постановление Министерства здравоохранения Республики Беларусь от 27.12.2006 № 120. - URL.: www.pharmacia.by/downloads/05.rtf

14. Об утверждении надлежащих фрармацевтических практик : Приказ Министра здравоохранения и социального развития Республики Казахстан от 27.05.2015 № 392. - URL.: https://tengrinews.kz/zakon/pravitelstvo_respubliki_kazahstan_premer_ministr_rk/zdravoohranenie/id-V1500011506

15. Об утверждении Технического регламента «О безопас-

\section{References}

1. Good Pharmacy Practice: standards for quality of pharmacy services (Joint FIP/WHO guidelines on GPP), 2011. Available from: http://zakon4.rada.gov.ua/ laws/ show/897_009. Ukrainian.

2. Ukrainian legislation. Available from: https:// zakon. rada.gov.ua. Ukrainian.

3. Podpruzhnykov YuV, Nemchenko AS, Andriukova LN, Humeniuk NY. Quality system and good practices in pharmacy. [Система качества и надлежащие практики в фрармации: учеб. Пособ.] Kyiv: TOV "SIK HRUP UKRAINA"; 2017. Russian.

4. Zdoryk OA. Development of standard operating procedures and their introduction in compounding pharmacies. Visnyk farmatsii. 2015;3: 56-9. Available from: https://doi.org/10.24959/nphj.15.2042.

5. Lebedinets VA, Kovalenko SN, Takhtaulova NA. [Regulation of document circulation in quality management system of the pharmaceutical enterprise]. Upravlinnia, ekonomika ta zabezpechennia yakosti $v$ farmatsii. 2011;5: 15-20. Ukrainian.

6. Leitlinien [Guidelines]. Available from: https://uwww.abda. de/themen/apotheke/qualitaetssicherungo/leitlinien/

7. Inspektionsprotokoll Drogerien [Inspections protocol drugstores]. Available from: https://www.gef.be.ch/gef/de/ index/direktion/organisation/kapa/formulare.assetref/dam/ documents/GEF/KAPA/de/CL_0510_02_D_V02_Inspro_ Dro \%20Mai2017.pdf. Switzerland.

8. Standard Operating Procedures (SOPs), 2016. Available from: https://www.thepsi.ie/gns/inspectionenforcement/inspections/InspectorsAdvice/SOPs.aspx

9. Community Pharmacy Benchmarking Guideline. Pharmaceutical Services Division, 2016. Available from: https:// www.pharmacy.gov.my/v2/sites/default/files/documentupload/community-pharmacy-benchmarking-guideline.pdf ности лекарственных средств для медицинского применения» : Постановление правительства Кыргызской Республики от 06.04.2011 № 137. - URL.: http://cbd. minjust.gov.kg/act/view/ru-ru/92533

16. Государственный стандарт Узбекистана. Надлежащая аптечная практика, 2016. - URL.: http:// www.uzpharm-control.uzl uploads/documents/doc3887-09-04-2018.pdf

17. Об утверждении Правил надлежащей аптечной практики лекарственных препаратов для медицинского применения : приказ Министерства здравоохранения Российской Федерации от 31.08.2016 № 647н. - URL.: http://pravo.gov.ru/proxy/ips/?docbody=\&nd =102421759

10. Setiawan D. Analisa Standar Operasional Prosedur CV. Apotek Lawang Gali. AGORA. 2018;1: 1-7.

11. Bhattacharya J. Guidance for Preparing Standard Operating Procedures (Sops). IOSR Journal of Pharmacy. 2015;1: 29-36.

12. The order of development of work instructions and standard operating procedures for pharmaceutical organizations of the Republic of Belarus, 2007. Available from: http://rceth.by/Documents/3mz6in2007 0918N050-0807.pdf. Russian.

13. Resolution of the Ministry of Health of the Republic of Belarus "On approval of Good Pharmacy Practice" from Dec 27, 2006, No. 120. Available from: www.pharmacia. by/downloads/05.rtf. Russian.

14. Order of the Ministtry of Health and Social Development of the Republic of Kazakhstan "On approval of Good Pharmaceutical Practices" of May 27, 2015 No. 392. Available from: https://tengrinews.kz/zakon/ pravitelstvo_respubliki_kazahstan_premer_ministr_rk/ zdravoohranenie/ id-V1500011506. Russian.

15. Resolution of the Government of the Kyrgyz Republic "On approval of the Technical Regulations "About safety of medicines for medical use" of Apr 06, 2011 No. 137. Available from: http://cbd.minjust. gov.kg/act/view/ruru/92533. Russian.

16. State standard of Uzbekistan. Good Pharmacy Practice, 2016. Available from: http://www.uzpharmcontrol.uz/uploads/documents/doc-3887-09-04-2018. pdf. Russian.

17. Order of the Ministry of Health of the Russian Federation "On approval of the Rules for good pharmacy practice of medicines for medical use" of Aug 31, 2016 No. 647n. Available from: http://pravo.gov. ru/proxy/ ips/?docbody=\&nd =102421759. Russian.

\section{Відомості про автора:}

Гала Л. О. - канд. фрармац. н., доцент кафедри організації та економіки фрармації, Національний медичний університет імені О. О. Богомольця, Київ, Україна. E-mail: hala.liliia@gmail.com, ORCID 0000-0002-0086-2706.

Information about the author:

Hala L. O. - PhD (Pharmacy), associate professor of the Organization and Economics of Pharmacy Department, O. Bohomolets National Medical University, Kyiv, Ukraine. E-mail: hala.liliia@gmail.com, ORCID 0000-0002-0086-2706.

ISSN 2312-0967. Фармацевтичний часопис. 2019. № 3 